\title{
Effect of the Polyethyleneimine Coating on the Bending Properties of the Natural Fiber-Reinforced Biocomposites
}

\author{
Madina Shamsuyeva* and Hans-Josef Endres \\ Institute of Plastics and Circular Economy IKK, Leibniz University Hannover, Germany
}

Submission: December 14, 2019; Published: January 08, 2020

*Corresponding author: Madina Shamsuyeva, Institute of Plastics and Circular Economy IKK, Leibniz University Hannover, Germany

\begin{abstract}
In the scope of this study woven flax fibers are coated with aqueous polyethyleneimine (PEI) solution, in order to improve the bending properties of the produced flax fiber-reinforced epoxy composite. The textiles are coated with the different concentrations of PEI solution and integrated into the biobased epoxy using hand impregnation with subsequent hot-press. The results show that 1 wt $\%$ and 5 wt $\%$ PEI can considerably improve the bending properties of the tested biocomposites.
\end{abstract}

Keywords: Natural Fibers; Polyethyleneimine; Biocomposites; Surface Treatments

\section{Introduction}

Cellulose-based fiber composites have already approved their beneficial performance in the fields of automotive (interior) and sport and leisure [1,2]. Compared with synthetic fiber-reinforced composites, biocomposites containing cellulose-based natural fibers as a reinforcement offer numerous material specific advantages, like e.g. low density and good specific mechanical properties [1,3] as well as a high damping coefficient [4]. Furthermore, growing environmental awareness promotes the use of materials based on renewable resources for technical applications. Firstly, manufacture of the natural fibers requires less energy than the manufacture of synthetic fibers, like e.g. carbon or glass [5]. Secondly, the biodegradability of the natural fibers and their incineration make them more advantageous with regard to effective recycling. In addition to the material properties and ecological aspects, there are further economic issues promoting introduction of these biocomposites into the market, namely, the possibility to manufacture natural fiber composites using the same equipment as for the conventional synthetic fiber composites, high material availability and diversity of available fiber types. At the same time, it should be considered that synthetic fiber industry has a long history, i.e. the mass production of glass fibers has been established since 1930s and high strength carbon fibers based on viscose rayon are industrially known since 1960s [6]. Consequently, the manufacturing stages for these materials are already optimized. In contrast, however, the market introduction of the natural fibers for technical applications has been actively encouraged since the last decades.Although in the past there have been several attempts [7].

Therefore, currently there are still numerous drawbacks limiting effective use of natural fiber composites in many applications. One of these disadvantages is poor fiber-matrix adhesion between natural fibers and polymer matrix. Specifically, due to the hydroxyl groups of the cellulose, natural fibers possess highly polar character, while polymer matrices used for composite manufacture are mostly nonpolar. This difference results in a low fiber-matrix adhesion within the composites leading to lower mechanical performance. There are various wetchemical approaches investigated in order to improve the fibermatrix adhesion [8-10]. The most commonly used methods are mercerization (surface treatment of fibers in a $\mathrm{NaOH}$ solution under tension) and use of numerous silane-based coupling agents. The diversity of the already known methods and variations of the applied procedures is induced by the chemical composition of the natural fibers, which differs with respect to the fiber type. i.e. the effectiveness of the applied method is strongly dependent on the chemical composition of the fiber surface. As an example, mercerization improves the mechanical properties of natural fibers containing lower amount of cellulose, because during this process, a part of the amorphous fiber components is removed, and the mass fraction of the cellulose is increased. However, the 
effectiveness of the mercerization with regard to the flax fibers, which already contain approx. $71 \%$ [8] of cellulose in their structure, is controversal and complex. [9].

In this context, there is a demand on a surface treatment method, which is less sensitive to the chemical composition of the natural fibers. Branched polyethyleneimine (PEI) is used in paper industry as a wet strength agent [11]. Several studies showed effective use of PEI as a coupling agent for wooden panels [12], cellulose-reinforced polypropylene [13], carbon fiber-reinforced epoxy [14,15] and cellulose nanofiber-reinforced epoxy [16]. According to the previous studies PEI reacts chemically with cellulose, although the exact reaction mechanism has not been understood yet [12]. Furthermore, it has been reported that PEI also reacts with the epoxy resin [16]. All of the reported studies state that the PEI enhances the mechanical performance of the investigated composite materials. Therefore, this approach offers a promising solution for the use in flax fiber-reinforced biobased epoxy composite, since among natural fibers flax possesses the highest mechanical performance and is currently most commonly used for composite applications [1,8,17]. The aim of this study is to investigate the effectiveness of the PEI coating of the flax fibers on the bending properties of the resulting biobased epoxy composites.

\section{Materials and Methods}

\section{Materials}

Twill woven flax fibers used as a reinforcement for the composite specimens are manufactured using double rapier weaving machine from the company Van de Wiele according to the same procedure described in the previous study [18]. The flax fiber staple yarn with a fineness of 200 tex and a twist of $200 \mathrm{~T} / \mathrm{mS}$ was delivered from a creel and processed without any modification. All of the chemicals are ordered from Sigma Aldrich. Branched PEI with average Mn (GPC) 1.800 and average $\mathrm{Mw}(\mathrm{LS}) \sim 2.000$ is delivered as an aqueous solution of $50 \mathrm{wt} \%$.

Table 1: Nomenclature of the tested specimens (EP - epoxy).
This solution is diluted using distilled water. The $\mathrm{pH} 10$ of the PEI solution is adjusted using $\mathrm{NaOH}$. $\mathrm{NaCl}$ is used as a salt for the PEI solution. The biobased epoxy resin with the trademark Greenpoxy 56 and the hardener based on 3-aminomethyl-3,5,5-trimethylcyclohexylamin with the trademark SD 8822 manufactured by Sicomin are ordered from Time Out. The cured epoxy resin contains around $38 \%$ of biobased carbon [19].

\section{Methods}

The flax fabrics are manufactured in a technical center at $20{ }^{\circ} \mathrm{C}$ and under a relative humidity of $65 \%$ in accordance with the ISO 139. In order to manufacture the twill weaved pattern, the warp yarn count was adjusted as $130 \mathrm{~T} / 10 \mathrm{~cm}$ and the weft as $90 \mathrm{~T} / 10 \mathrm{~cm}$ ( $\mathrm{T}$ - threads). The detailed information about the manufacture of this fabric has already been reported in the previous study [18]. The woven textiles are fixed using a wooden frame. An aqueous solution of the PEI is sprayed on the both sides of the textile using a spray gun. Afterwards the frames with the coated fabrics are placed into circulating air oven at $80{ }^{\circ} \mathrm{C}$ for $24 \mathrm{~h}$. In order to manufacture composites, the coated fabrics are removed from the frame and cut into pieces with the dimensions of $25 \times 20 \mathrm{~cm}$. The distance between the cut textiles used for the experiments and the frame is set as $2 \mathrm{~cm}$. The fabrics are carefully impregnated with a priorly degassed epoxy mixture using rollers and put into the mould. Each composite specimen includes 8 flax fabrics. Finally, the composite specimens are pressed for $30 \mathrm{~min}$ at $80{ }^{\circ} \mathrm{C}$ under the pressing force of $250 \mathrm{kN}$. The fiber mass fraction of the composites is adjusted as $78-80 \%$. This extremely high mass fraction enhances the influence of the fiber-matrix adhesion on the mechanical performance of the resulting composites. The cured composites are cooled down to the room temperature using water cooling directly in the mould. The tested specimens with the dimensions of $80 \times 15 \mathrm{~mm}$ (length $\mathrm{x}$ width) are cut out of the composites using a diamond sample saw. The summary and the nomenclature of analyzed specimens is presented in (Table 1).

\begin{tabular}{|c|c|c|}
\hline Specimen & Nomenclature (fabrics) & Nomenclature (composites) \\
\hline Flax without modification & FLA & FLA \\
\hline Flax coated with 0,5 wt $\%$ PEI & FLA-0,5 PEI & FLA-EP-0,5 PEI \\
\hline Flax coated with $1 \mathrm{wt} \%$ PEI & FLA-1 PEI & FLA-EP-1 PEI \\
\hline Flax coated with 5 wt $\%$ PEI & FLA-5 PEI & FLA-EP-5 PEI \\
\hline Flax coated with 15 wt $\%$ PEI & FLA-15 PEI & FLA-EP-15 PEI \\
\hline Flax coated with $30 \mathrm{wt} \% \mathrm{PEI}$ & FLA-30 PEI & FLA-EP-30 PEI \\
\hline Flax coated with $50 \mathrm{wt} \% \mathrm{PEI}$ & FLA-50 PEI & FLA-EP-50 PEI \\
\hline
\end{tabular}

The coated fabrics and the manufactured composite specimens are subjected to the following testing methods: digital microscope imaging, density measurement and bending testing. The microscope imaging is performed using a 3D-Digital microscope VHX 5000 Keyence at the If BB Institute for Bioplastics and Biocomposites. The density measurement is conducted using buoyancy method with ethanol. Finally, the three-point bending test is performed according to the ISO 14125 using the machine Zwick/Roell Z2,5KNTN with a measuring cell 2,5 kN and a testing speed of $1 \mathrm{~mm} / \mathrm{min}$. The specimens are conditioned prior to the 
testing at $23^{\circ} \mathrm{C}$ and under a relative humidity of $50 \%$ for $88 \mathrm{~h}$. The composites are tested in two directions, namely, weft and warp. The placement of the corresponding specimens is represented in (Figure 1). The values reported in this study represent a mean value of five tested specimens.

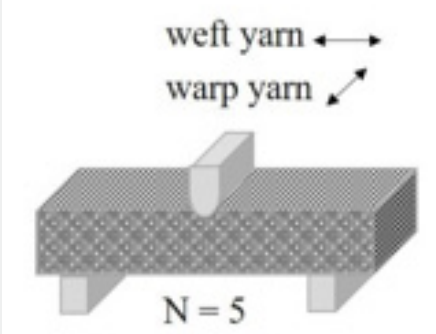

Bending testing in weft direction

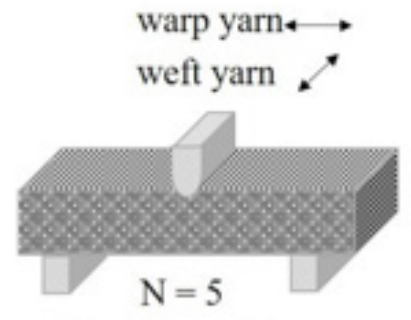

Bending testing in warp direction

Figure 1: Schematic representation of the testing direction of the composite specimens ( $\mathrm{N}$ - number of tested specimens).

\section{Results and Discussion}

\section{Microscope Imaging of the Coated Fabrics}

The digital microscope images of the PEI coated flax textiles are represented in the (Figure 2). These images show that the PEI coating changes the color of the fabric making it browner. The increase of the PEI concentration leads to a darker brown color. The browning of the coated fabric is caused by the Maillard reaction between sugar and PEI [20]. According to the literature the cellulose-PEI mixture subjected to the increasing temperature shows no color change at $50{ }^{\circ} \mathrm{C}$, a light brown color is observed at $100{ }^{\circ} \mathrm{C}$ and dark brown at $160^{\circ} \mathrm{C}[12]$. Since in this study the PEI coated fabrics are dried at $80^{\circ} \mathrm{C}$, the discoloration represents an expected reaction of the coating. It has already been shown in the previous studies that at the microscopic level the PEI is adsorbed on the cellulose surface as particles and not as a layer $[19,21]$. The amount of the PEI adsorbed on 8 flax fabrics used for the manufacture of one composite specimen is listed in the (Table 2). The amount of the PEI adsorbed on the fiber surface is analyzed gravimetrically by weighting the fabric before and after the PEI coating. The results show that the amount of the adsorbed PEI increases proportionally to the used concentration until the concentration values of $15 \mathrm{wt} \%$ is used. Probably, the use of too high amount of PEI leads to the displacement and agglomeration of the PEI towards the wooden frame. Consequently, the textile samples used for composite manufacture contained only a part of the sprayed PEI.

Table 2: Amount of the PEl adsorbed on the 8 fabrics processed.

\begin{tabular}{|c|c|c|}
\hline Sample & PEI (g) / 8 fabrics & Density $\mathbf{( g / \mathbf { c m } ^ { 3 } )}$ \\
\hline Ref & 0 & $1,25 \pm 0,03$ \\
\hline FLA-0,5 PEI & 0,5 & $1,40 \pm 0,02$ \\
\hline FLA-1 PEI & 3,4 & $1,32 \pm 0,02$ \\
\hline FLA-5 PEI & 18,3 & $1,27 \pm 0,03$ \\
\hline FLA-15 PEI & 41,3 & $1,30 \pm 0,03$ \\
\hline FLA-30 PEI & 49,1 & $1,31 \pm 0,04$ \\
\hline FLA-50 PEI & 49,7 & $1,22 \pm 0,05$ \\
\hline
\end{tabular}

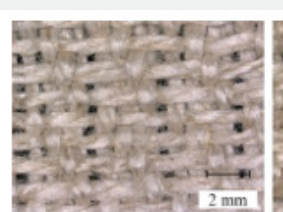

FLA

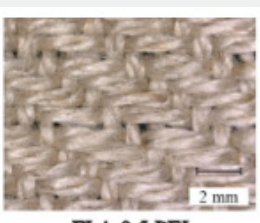

FLA-0,5 PEI

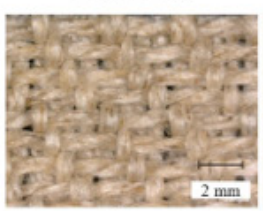

FLA-15 PEI

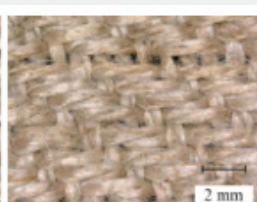

FLA-1 PEI

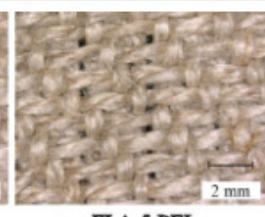

FLA-5 PEI

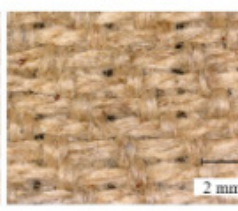

FLA-30 PEI

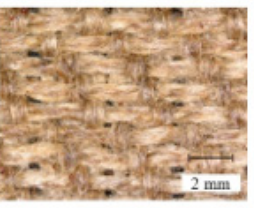

FLA-50 PEI

Figure 2: Digital microscope images of the flax fabrics coated with different concentrations of PEI. 


\section{Density Measurement of the Biocomposites}

The results of the density measurement are also presented in the (Table 2). Nearly all of the fabrics coated with PEI possess higher density than the reference sample. The highest density values correspond to the composites, which include flax fabrics coated with 1 wt $\%$ and 5 wt $\%$ PEI, $1,40 \mathrm{~g} / \mathrm{cm}^{3}$ and 1,32 g/ $\mathrm{cm}^{3}$, respectively. Furthermore, it could be said that the further increase of the PEI concentration leads tendentially to the lower mean density values with higher standard deviation. Since PEI reacts both with cellulose [12] and with epoxy [16], possibly the lower concentration of PEI promotes better infiltration of the textiles with the epoxy resin. Consequently, this results in a lower amount of air inclusions inside the composites and thus, a higher density compared with the reference. PEI remains as an agglomerate on the fiber surface $[19,21]$ and in the composite [19] and the chemical reaction with epoxy takes place merely at the interphase between the PEI agglomerate and epoxy resin [16].
Therefore, it can be assumed, that the higher PEI concentration leads to the formation of large agglomerates, which remain at the fiber-matrix interphase unreacted and act as contamination. These contaminations disturb the quality of the fiber-matrixinterphase and can lead to the formation of air inclusions between them. In order to prove this assumption, the cross-sections of the composite specimens were subjected to microscope imaging. The microscope images of the cross-sections are demonstrated in (Figure 3). A very strong defibrillation can be observed at the cross-section of the reference sample specifying very low impregnation with the polymer matrix. This is caused by the high fiber-matrix-fraction and poor fiber-matrix adhesion. The specimens with the fabric coated with $0,5 \mathrm{wt} \%, 1 \mathrm{wt} \%, 5 \%$ and $15 \mathrm{wt} \%$ of PEI possess significantly less defibrillation in crosssection, with the $15 \mathrm{wt} \%$ leading to the best result. The specimens with higher PEI concentrations have numerous air bubbles in their cross-section, explaining the reduction of the density and high deviation of the measured density values.

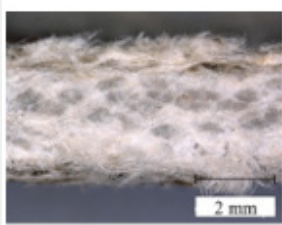

FLA-EP
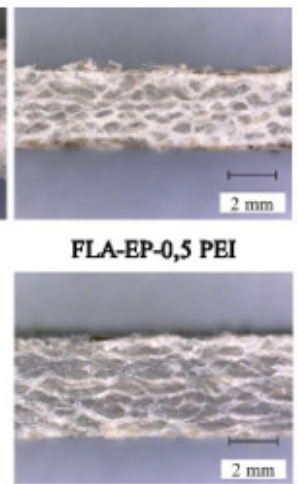

FLA-EP-15 PEI

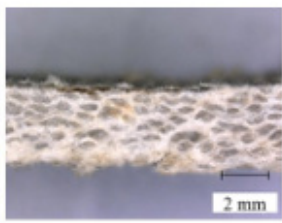

FLA-EP-1 PEI

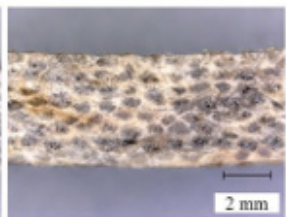

FLA-EP-30 PEI

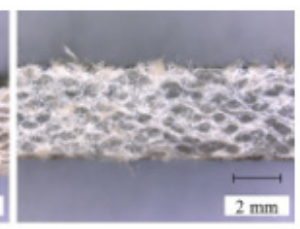

FLA-EP-5 PEI

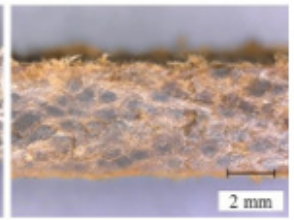

FLA-EP-50 PEI

Figure 3: Digital microscope images of the cross-section of the tested composites.

\section{Bending Properties}

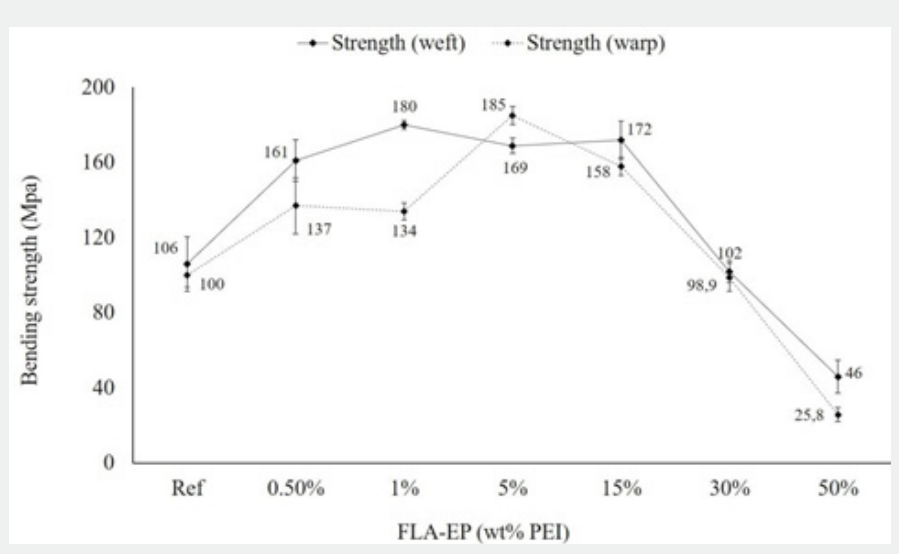

Figure 4: Bending strength of the tested composite specimens. 
The bending strength of the composites tested in warp and weft directions is presented in the (Figure 4). The values of the reference composites showing $100 \mathrm{MPa}$ and $106 \mathrm{MPa}$ are comparable with the literature values of unidirectional flax fiberreinforced epoxy composites possessing strength of $190 \mathrm{MPa}$ and $218 \mathrm{MPa}[9]$. The results show that the PEI coating leads to the improvement of the bending strength in both testing directions. The overall tendency that nearly all of the values in weft direction are higher than those in warp direction can be explained by the parameters used for the textile manufacture incl. twist of the used yarns, yarn counts, resulting crimp, etc. [18]. In the weft direction the $1 \mathrm{wt} \%$ PEI results in the highest bending strength, which is approx. $70 \%$ higher than the corresponding reference. The further increase of the PEI concentration, like e.g. $15 \mathrm{wt} \%$, leads to lower and / or unstable results. In the warp direction the highest value of $185 \mathrm{MPa}$, which is $85 \%$ higher than the refence, is achieved using $5 \mathrm{wt} \%$ PEI. Starting from the $15 \mathrm{wt} \%$ the PEI coating reduced the bending strength of the composites drastically, so that the extreme high concentration of $50 \mathrm{wt} \%$ results in values considerably lower than the refences. The bending modulus of the tested composites is presented in the (Figure 5). In general, the tendency is comparable with that of the bending strength, i.e. the mild concentrations of PEI, namely $1 \mathrm{wt} \%$ and $5 \mathrm{wt} \%$, lead to the highest improvement of the bending modulus, while higher concentrations reduce the modulus extremely. According to the density measurement and microscope images of the cross-sections of the specimens this extreme reduction of the bending properties is caused by air inclusions, and probably by the PEI agglomerates acting as a contamination at the fiber-matrix-interphase.

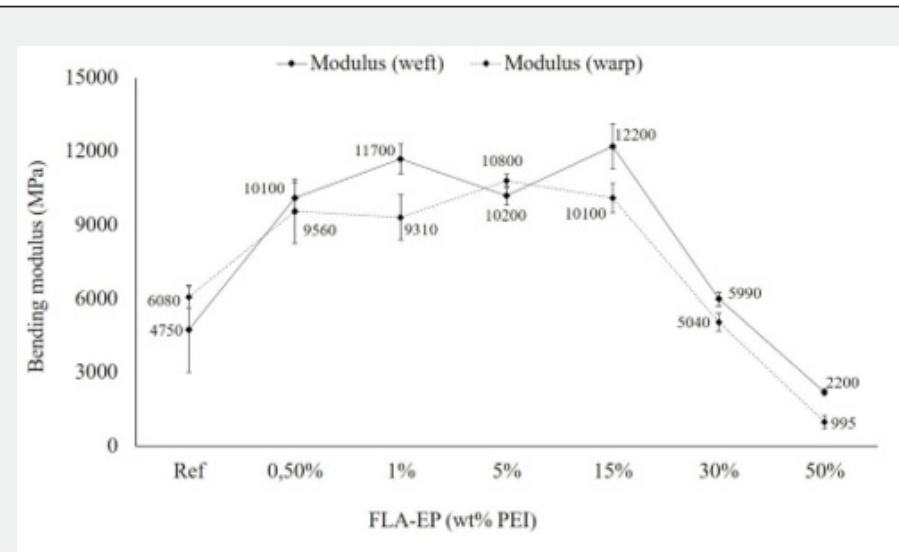

Figure 5: Bending modulus of the tested composite specimens.

\section{Conclusion}

In this study the influence of the PEI coating is investigated with regard to the improvement of bending properties of the flax fiber-reinforced biobased epoxy resin. The results show that the PEI concentrations of $1 \mathrm{wt} \%$ and $5 \mathrm{wt} \%$ represent an optimal concentration range. Depending on the tested direction the concentrations lead to the increase of the bending strength to about $70 \%$ or $85 \%$. At the same time the PEI coating has a minimal effect on the density of the resulting composites corresponding to an increase of about $2 \%$ to $5 \%$. Although the main findings of this study show that the PEI coating offers a promising solution for the use as a coupling agent in the natural fiber-reinforced composites, there are still a lot of scientific questions, which have to be answered, in order to realize the potential of this approach. As an example, further optimization of the applied procedure with regard to the smaller concentration steps, used coating method, e.g. dipping instead of spraying, as well as the used substrate, e.g. plain, satin weaved fabric or unidirectional fabric would provide a good basis for the further research. Due to the large number of the influential parameters involved, probably, the use of Design of Experiments would be a suitable approach to carry out such an extensive and systematic study.

\section{Acknowledgement}

This study was performed at the Fraunhofer Application Center HOFZET® of the Fraunhofer Institute for Wood Research WKI in Hanover.

The authors appreciate the financial support provided by the Ministry for Science and Culture of the State of Lower Saxony (MWK) for the implementation of the project "ProBio" and particularly this feasibility study. The authors would like to thank Prof. Henning Menzel from the Technical University Braunschweig, Institute of Technical Chemistry. for the valuable discussions during the implementation of this study. Furthermore, the authors would like to thank everyone involved in making the experiments and testing. Special thanks go to Mr. Ricardo Wege and Mrs. Jana Winkelmann (fabric production) and Tim-Maximilian Federer (density measurement), Tanja Rudeck (composite manufacture) and Mr. Rafael Gaida from Institute for Bioplastics and Biocomposites (bending tests)."

\section{References}

1. Ahmad F, Choi HS, Park MK (2015) A Review: Natural Fiber Composites Selection in View of Mechanical, Light Weight, and Economic Properties, Macromol Mater Eng 300: 10-24. 
2. Mohammed L, Ansari MNM, Pua G, Jawaid M, Islam MS (201) A Review on Natural Fiber Reinforced Polymer Composite and Its Applications. Int J Polym Sci:1-15.

3. Sanjay MR, Madhu P, Jawaid M, Senthamaraikannan P, Senthil S, et al. (2018) Characterization and properties of natural fiber polymer composites: A comprehensive review, J Clean Prod 172: 566-581.

4. Duc F, Bourban PE, Plummer CJG, Månson JAE (2014)Damping of thermoset and thermoplastic flax fibre composites. Compos Part AAppl S 64: 115-123.

5. Song YS, Youn JR, Gutowski TG (2009) Life cycle energy analysis of fiber-reinforced composites, Compos. Part A-Appl S 40: 1257-1265.

6. Kulshreshtha AK (2002) Handbook of polymer blends and composites, $1^{\text {st }}$ ed., RAPRA Technology, Shrewsbury, UK.

7. Pickering KL, Efendy MA, Le TM (2016) A review of recent developments in natural fibre composites and their mechanical performance Compos Part A-Appl S 83: 98-112.

8. Li X, Tabil LG, Panigrahi S (2007) Chemical Treatments of Natural Fiber for Use in Natural Fiber-Reinforced Composites: A Review. J Polym Environ (Journal of Polymers and the Environment) 15: 25-33.

9. Van de Weyenberg I, Chi Truong T, Vangrimde B, Verpoest I (2006) Improving the properties of UD flax fiber reinforced composites by applying an alkaline fiber treatment. Compos Part A-Appl S 37: 13681376.

10. Lopattananon N, Panawarangkul K, Sahakaro K, Ellis B (2006) Performance of pineapple leaf fiber-natural rubber composites: The effect of fiber surface treatments. J Appl Polym Sci 102: 1974-1984.

11. Farbenindustrie AG (1942) A method for improving materials based on paper fibers.

12. Fabo A (2004) Untersuchungen zur Wechselwirkung von Polyethylenimin (PEI) mit Holzkomponenten. Dissertation, Hamburg, Germany.

13. González Sánchez C, González-Quesada M, De la Orden MU, Urreaga JM (2008) Comparison of the effects of polyethylenimine and maleated polypropylene coupling agents on the properties of cellulosereinforced polypropylene composites. J Appl Polym Sci 110: 25552562.
14. Ma L, Meng L, Wu G, Wang Y, Zhao M, et al. (2015) Improving the interfacial properties of carbon fiber-reinforced epoxy composites by grafting of branched polyethyleneimine on carbon fiber surface in supercritical methanol. Compos Sci Technol 114: 64-71.

15. Tang XZ, Yu B, Hansen RV, Chen X, Hu X, et al. (2015) Grafting Low Contents of Branched Polyethyleneimine onto Carbon Fibers to Effectively Improve Their Interfacial Shear Strength with an Epoxy Matrix. Adv Mater Interfaces 2(12): 1500122.

16. Zhao J, Li Q, Zhang X, Xiao M, Zhang W, et al. (2017) Grafting of polyethyleneimine onto cellulose nano fibers for interfacial enhancement in their epoxy nanocomposites, Carbohydr Polym 157: 1419-1425.

17. Mohanty AK, Misra M, Hinrichsen G (2000) Biofibers, biodegradable polymers and biocomposites: An overview. Macromol Mater Eng 276277(1): 1-24.

18. Shamsuyeva, Winkelmann, Endres (2019) Manufacture of Hybrid Natural/Synthetic Fiber Woven Textiles for Use in Technical Biocomposites with Maximum Biobased Content, J Compos Sci 3(2): 43.

19. Shamsuyeva M (2019) Oberflächenmodifizierung von cellulose basierten Fasern für den Einsatz in Ver- bundwerkstoffen. Dissertation, Braunschweig, Germany.

20. Angrick M, Rewicki D (1980) Die Maillard Reaktion. Chem Unserer Zeit 14(5): 149-157.

21. Petlicki J, Van de Ven TGM (1994) Adsorption of polyethylenimine onto cellulose fibers. Colloids Surf, A Physicochem Eng Asp. 83: 9-23.

22. Goutianos S, Peijs T, Nystrom B, Skrifvars M, (2006) Development of Flax Fibre based Textile Reinforcements for Composite Applications, Appl Compos Mater 13: 199-215.

23. Rajan R, Rainosalo E, Ramamoorthy SK, Thomas SP, Zavašnik J, et al (2018) Mechanical, thermal, and burning properties of viscose fabric composites: Influence of epoxy resin modification. J Appl Polym Sci 135(36): 46673.

\section{Your next submission with Juniper Publishers} will reach you the below assets

- Quality Editorial service

- Swift Peer Review

- Reprints availability

- E-prints Service

- Manuscript Podcast for convenient understanding

- Global attainment for your research

- Manuscript accessibility in different formats

( Pdf, E-pub, Full Text, Audio)

- Unceasing customer service

Track the below URL for one-step submission

https://juniperpublishers.com/online-submission.php 